\title{
Author Correction: Computational models link cellular mechanisms of neuromodulation to large-scale neural dynamics
}

James M. Shine (D), Eli J. Müller (D), Brandon Munn (D), Joana Cabral (D), Rosalyn J. Moran and Michael Breakspear (D)

Correction to: Nature Neuroscience https://doi.org/10.1038/s41593-021-00824-6, published online 6 May 2021.

In the version of this article initially published, the image credit for Fig. $3 \mathrm{f}$ was omitted, and the related reference (van den Brink, Pfeffer \& Donner, 2019) was missing. The errors have been corrected in the PDF and HTML versions of this article.

Published online: 21 June 2021

https://doi.org/10.1038/s41593-021-00891-9

๑ The Author(s), under exclusive licence to Springer Nature America, Inc. 2021 